\title{
Costs of sea dikes - regressions and uncertainty estimates
}

\author{
Stephan Lenk ${ }^{1}$, Diego Rybski ${ }^{1}$, Oliver Heidrich ${ }^{2}$, Richard J. Dawson ${ }^{2}$, and Jürgen P. Kropp ${ }^{1,3}$ \\ ${ }^{1}$ Potsdam Institute for Climate Impact Research - PIK, Member of Leibniz Association, P.O. Box 601203, \\ 14412 Potsdam, Germany \\ ${ }^{2}$ School of Civil Engineering \& Geosciences \& Tyndall Centre for Climate Change Research, Newcastle University, \\ Newcastle upon Tyne NE1 7RU, UK \\ ${ }^{3}$ University of Potsdam, Institute of Earth and Environmental Science, Potsdam, Germany \\ Correspondence to: Diego Rybski (ca-dr@ rybski.de)
}

Received: 12 August 2016 - Discussion started: 26 August 2016

Revised: 14 February 2017 - Accepted: 13 March 2017 - Published: 29 May 2017

\begin{abstract}
Failure to consider the costs of adaptation strategies can be seen by decision makers as a barrier to implementing coastal protection measures. In order to validate adaptation strategies to sea-level rise in the form of coastal protection, a consistent and repeatable assessment of the costs is necessary. This paper significantly extends current knowledge on cost estimates by developing - and implementing using real coastal dike data - probabilistic functions of dike costs. Data from Canada and the Netherlands are analysed and related to published studies from the US, UK, and Vietnam in order to provide a reproducible estimate of typical sea dike costs and their uncertainty. We plot the costs divided by dike length as a function of height and test four different regression models. Our analysis shows that a linear function without intercept is sufficient to model the costs, i.e. fixed costs and higher-order contributions such as that due to the volume of core fill material are less significant. We also characterise the spread around the regression models which represents an uncertainty stemming from factors beyond dike length and height. Drawing an analogy with project cost overruns, we employ log-normal distributions and calculate that the range between $3 x$ and $x / 3$ contains $95 \%$ of the data, where $x$ represents the corresponding regression value. We compare our estimates with previously published unit costs for other countries. We note that the unit costs depend not only on the country and land use (urban/non-urban) of the sites where the dikes are being constructed but also on characteristics included in the costs, e.g. property acquisition, utility relocation, and project management. This paper gives decision makers an order of magnitude on the protection costs, which can help to remove potential barriers to develop-
\end{abstract}

ing adaptation strategies. Although the focus of this research is sea dikes, our approach is applicable and transferable to other adaptation measures.

\section{Introduction}

Sea-level rise represents a foreseeable consequence of climate change and there is considerable interest in comparing coastal flood damage with adaptation costs (Hallegatte et al., 2013; Boettle et al., 2013b). In line with rising temperature and sea levels, more frequent and severe storm surges need to be anticipated (Menéndez and Woodworth, 2010). The construction of dikes and similar defensive measures has a long history and coastal protection represents a conventional means to adapt to the threat of sea-level rise (Jonkman et al., 2013). In 1990 it was estimated that protecting $360000 \mathrm{~km}$ of the coasts globally against a $1 \mathrm{~m}$ sea-level rise would cost at least USD 500 billion over a 100-year period (Dronkers et al., 1990).

In order to estimate costs and benefits of adaptation to sealevel rise (Fankhauser, 1995; Jonkman et al., 2004; Dawson et al., 2009, 2011; Klijn et al., 2012; Boettle et al., 2013a; Eijgenraam et al., 2014; Jongmann et al., 2014; Kind, 2014; Kreibich et al., 2014; Boettle et al., 2016), various categories are required - in particular (i) the change of frequency and magnitude of coastal floods (Eijgenraam et al., 2014; Dawson and Hall, 2006; Vousdoukas et al., 2016), (ii) the expected (direct, monetary) damage without adaptation (Bouwer, 2013; Prahl et al., 2016), (iii) the residual (direct, monetary) damage with adaptation (Kreibich et al., 
2014), and (iv) the construction costs of the adaptation measure (Jonkman et al., 2013; Aerts et al., 2013).

While the climate impact and adaptation research community has made progress in assessing the categories (i)-(iii), the construction costs of protection measures (category iv) are poorly reported in the literature. These are considered an engineering problem yet are also of utmost importance for decision makers in order to assess the scale of the investment that is required to provide protection and is achievable for the resources available. Failure to consider the costs of strategies can invalidate, or at least expose as impractical, recommendations from research studies. However, engineers hesitate to provide general and transferable costs. Academic literature is lacking "real-life" auditable cost information on adaptation measures (Heidrich et al., 2013) which can be of use to international, national, and local decision makers. Indeed, providing an order of magnitude and reducing uncertainties on the protection costs can remove potential barriers in designing and implementing adaptation strategies (Reckien et al., 2015; Heidrich et al., 2016).

One way to investigate construction costs is to study similar dikes that were planned or constructed in the past. Using historic construction costs is referred to as the elemental costs projection approach (BCIS, 2012). However, civil engineering works are profoundly influenced by factors such as scale, nature, and characteristics of the project. This means that a straightforward use of this approach is not always sensible as rates, prices, and discounts can fluctuate dramatically over short periods of time and between projects (MacDonald, 2013). For various reasons a synthesis of coastal protection costs is very limited. On the one hand, the costs of coastal protection projects in different countries and regions are affected by socio-economic conditions like land value, land use, building prices, gross domestic product (GDP), and the level of income. On the other hand, the comparability of projects is often hindered by heterogeneity and a lack of information about the site and project specifics, e.g. site preparation, site access, and material sourcing. In addition, defence measures differ in engineering, design, and specific features like detailed dimensions and unit costs are not reported in the academic literature. Thus, it is difficult to make generalised estimates of the costs of a sea dike project of length $l$ and height $h$ at a given site and country.

Most authors studying adaptation to sea-level rise and adjunctive costs refer to Hoozemans et al. (1993) or Jonkman et al. (2013). The former estimated unit costs for three coastal protection measures according to the Dutch standard including dike design, construction, taxes, fees, levies, and royalties (Hoozemans et al., 1993). The latter investigated costs for coastal protection of low-lying delta areas using projectoriented case studies for the Netherlands, New Orleans, and Vietnam (Jonkman et al., 2013). The authors estimated unit costs for constructing and raising different types of hard and soft coastal protection measures and analysed the relationship between dike height, dike cross section, and costs of raising dikes. Based on data from three countries it has been suggested that the estimates from Hoozemans et al. (1993) significantly overestimate the costs of constructing dikes (Linham et al., 2010).

Many of the above-mentioned studies use "unit costs", i.e. the dike costs can be expressed per metre height. This, however, implies the assumption that there is a linear relation without fixed costs - an assumption that to our knowledge has not been supported quantitatively so far. In addition, uncertainty is at most quantified in terms of a range, i.e. some upper or lower values. This paper significantly extends these approaches by developing probabilistic functions of dike costs and implementing them using real coastal dike data.

In order to provide a reproducible assessment of typical protection costs and their uncertainties, the work reported here explores estimated construction costs for sea dikes in Canada (Metro Vancouver) and in the Netherlands. We address two questions. First, what is the appropriate functional form for the costs of a sea dike as a function of its height? Since both the footprint and the volume are proportional to the height of a dike, the costs of a unit of fixed length should increase linearly and quadratically with the height, respectively, leading to the question of the composite "functional form".

Second, what is the range of uncertainty that needs to be considered? Although our findings are related to sea dikes, our research approach and determination of uncertainty is potentially applicable and transferable to other adaptation measures. In the research on climate change adaptation, the constraints related to quantifying coastal protection costs listed above represent an uncertainty which needs to be taken into account when cost effectiveness of adaptation measures is studied.

In order to quantify the uncertainty of the dike construction costs, we draw a parallel with project cost overruns. Construction projects usually exhibit a difference between forecasted and actual construction costs (Flyvbjerg, 2007a, b; Flyvbjerg and Stewart, 2012). These differences can have various origins, e.g. unexpected site conditions, unforeseen events, and overall underlying complexity associated with the design and construction process (Love et al., 2013). Since cost overruns represent uncertainties, which the estimator is aware of but cannot know their magnitude, they are sometimes referred to as "known-unknowns". Chou et al. (2009) demonstrated that log-normal distributions best fit the probabilistic costs of highway bridge replacement projects. Thus, here our starting point is to characterise the deviations (spread) around typical dike construction costs as a lognormal distribution. 


\section{Data}

We base our main analysis on two data sources, namely Cost of Adaptation - Sea Dikes \& Alternative Strategies (Delcan Corporation, 2012) for Canada (Metro Vancouver) and Kosten van maatregelen - Informatie ten behoeve van het project Waterveiligheid 21e eeuw (de Grave and Baase, 2011) for the Netherlands. The advantage is that the data these reports contain are homogeneous (at least within each of both reports) since the cost figures come from the same sources and the same case studies, and they relate to similar constructions, i.e. sea and estuarine dikes. Moreover, local conditions, e.g. affecting the exact shape of the dikes, have been taken into account.

\subsection{Canada}

Estimated costs to protect Vancouver and neighbouring municipalities against sea-level rise by 2100 are provided by Delcan Corporation (2012) - for a summary see Sect. A1. The protection measures are subdivided into 36 shoreline reaches of more than $250 \mathrm{~km}$ length between the Burrard Inlet and Boundary Bay. A reach is a general term for a length of a stream or river, usually suggesting a level, uninterrupted stretch. The Canadian report provides estimates in the preparation phase and we do not have any information about whether any of the planned dike has actually been constructed to date. Since it is not specified, we assume all costs are given in 2012 Canadian dollars (CAD).

The costs presented in the Canadian study are referred to as a "class D estimate" (Delcan Corporation, 2012). According to Public Works and Government Services Canada this means an indicative estimate giving unit costs based on a comprehensive assumptions and project requirements list. This kind of estimate is developed during the project feasibility and design stage (Public Works and Government Services Canada) and therefore subject to change.

Table 4.3A and B in Delcan Corporation (2012) list the length and estimated costs separated for each dike, which allows us to calculate the costs per unit length. In addition, Table 2.1 in Delcan Corporation (2012) provides information about the expected flood levels in 2100 and the required increase of the dike height or the height of the dike to be built. Accordingly, we can study the costs per length as a function of the height, i.e. CAD per length in metres vs. height in metres. Eight of the reaches with bespoke features (e.g. barrier; see Sect. A1) have been excluded from the analysis. Additional information is included on whether the dikes are to be raised or newly constructed and whether the corresponding site is urban or rural.

As detailed in Sect. A1, the costs consist of (i) structural flood protection/embankment; (ii) utility relocation, pump stations, and flood boxes; (iii) property acquisition; (iv) seismic resilience measures; (v) environmental compensation; and (vi) site investigation, project management, and engineering.

\subsection{Netherlands}

The Dutch report (de Grave and Baase, 2011) provides the estimated costs needed to raise the height of dikes across the Netherlands in order to decrease the estimated risk of flooding by a factor of 10 relative to the present protection level. The estimates are broken down into 205 dikes of more than $2600 \mathrm{~km}$ length and the associated costs are estimated for several steps of raising the dike height $(25,50,100,200 \mathrm{~cm})$, depending on the need.

Tables $\mathrm{G}$ and $\mathrm{K}$ in de Grave and Baase (2011) list the length, the height steps, and the associated cost estimates for two different scenarios. The first scenario assumes the flood risks according to the current installed protection and the current Dutch legislation. The second scenario takes into account the improvement of flood protection planned between 2015 and 2020. According to Eijgenraam and Zwaneveld (2011) the second scenario is the more realistic one and the first is an underestimate. As, in addition, the second scenario is based on more recent developments, we choose to use only the cost estimates from the second scenario in this study.

As detailed in Sect. A2 the costs consist of (i) ground work and construction measures per unit length, (ii) special measures, (iii) adjustment or relocation of infrastructure, (iv) land acquisition, (v) environmental compensation, and (vi) additional costs for operations and maintenance.

\section{Analysis}

In the following we fit regressions to the data, quantify the uncertainty, and compare our results with previously published estimates.

\subsection{Regressions}

In Fig. 1 we plot the costs per metre length of dike as a function of raising the height of the dikes. For the Canadian data (Fig. 1a) it can be seen that the costs are spread over a wide range roughly between 5000 and $40000 \mathrm{EUR} \mathrm{m}^{-1}$ for dike construction (or raise) with final heights of 1 to $5 \mathrm{~m}$. Only a weak tendency of reduced costs for lower heights can be inferred visually from Fig. 1. The correlation coefficient is $\varrho_{\mathrm{p}}=0.43[0.07,0.69]$ ([.] denotes $95 \%$ confidence). For the Netherlands (Fig. 1b) the spread is overall smaller but most of the constructions are lower than $1 \mathrm{~m}$ and only a few values are available for a raise of roughly $3 \mathrm{~m}$. Here, the correlation coefficient is $\varrho_{\mathrm{p}}=0.79[0.74,0.84]$.

In order to find a suitable model for typical costs we test four regressions, namely (i) linear without intercept (LWI), (ii) linear polynomial (LP), (iii) quadratic polynomial (QP), 


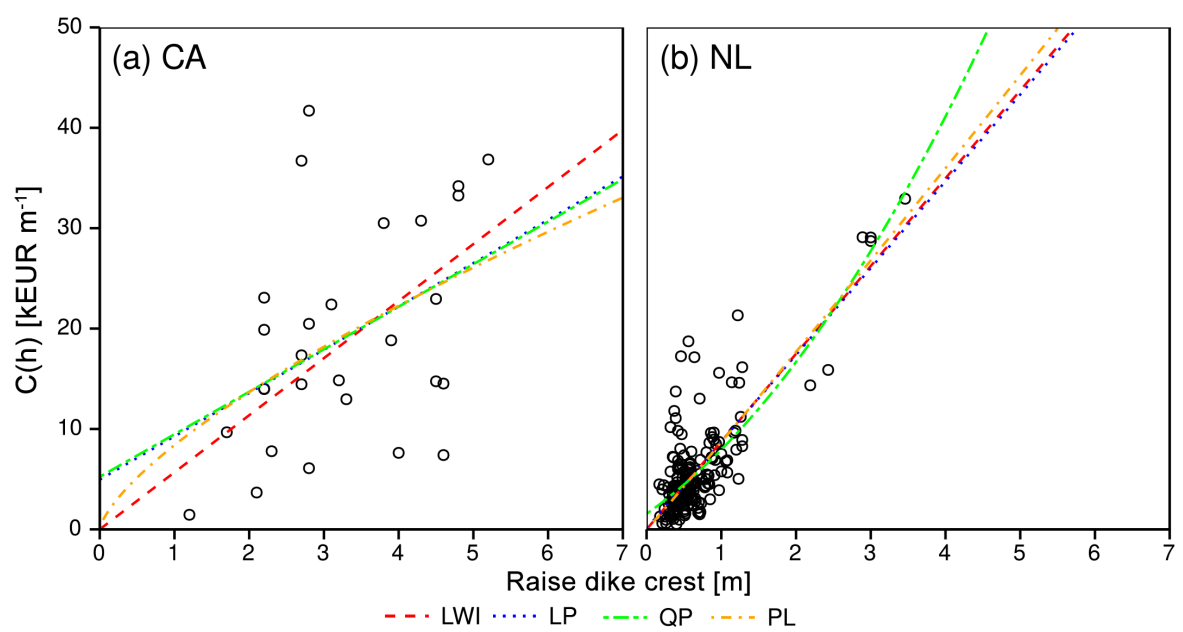

Figure 1. Plot of dike costs versus crest height for all dikes with a linear fit without intercept, LWI (Eq. 1, red dashed line), a linear polynomial fit, LP (Eq. 2, blue dotted line), a quadratic polynomial fit, QP (Eq. 3, green double dashed line), and a power-law fit, PL (Eq. 4, orange dotted dashed line). (a) Twenty-eight Canadian dikes with the obtained fits and (b) 205 dikes in the Netherlands with the obtained fits. The linear and quadratic polynomials collapse in (a) and the linear without intercept with the linear polynomial in (b); see main text.

and (iv) power law (PL):

$$
\begin{aligned}
\text { LWI: } C(h) & =b h, \\
\text { LP: } C(h) & =a+b h, \\
\text { QP: } C(h) & =a+b h+c h^{2}, \\
\text { PL: } C(h) & =b h^{\beta},
\end{aligned}
$$

where $C(h)$ (in EUR m ${ }^{-1}$ ) is the dike cost per metre length and $h$ is height (in m). $a, b, c$, and $\beta$ are parameters, where $a$ denotes the intercept (fixed costs, which are independent of the dike height), $b$ the slope, also known as unit costs (Hoozemans et al., 1993; Jonkman et al., 2013), $c$ the quadratic term, and $\beta$ the exponent of the power law. The parameters have corresponding units, such as EUR $\mathrm{m}^{-3}$ for $c$. For simplicity, we omit the units of the parameters. Following Hudson et al. (2015), cost elements can be well split into (1) planning and design costs, e.g. consulting and survey costs; (2) capital costs, e.g. enabling and construction costs; (3) inspection costs, e.g. operational, public safety and monitoring program costs; and (4) maintenance costs, e.g. maintenance and replacement costs.

Equation (1) is the simplest form, i.e. a linear relation with slope $b$ starting at $0 \mathrm{EUR} \mathrm{m}^{-2}$ for $h=0 \mathrm{~m}$. In principle, even for very small projects, costs can emerge independent of the actual height (fixed costs) due to e.g. planning. Thus, Eq. (2) is similar to Eq. (1) but has an offset, i.e. the intercept $a$, which is linked to the preparation costs. Since the volume of the dike is proportional to the square of its height (see item $1 b$ in Sect. A1), an additional quadratic term (see e.g. Diaz, 2016 ) in Eq. (3) leads to a second-order polynomial. Finally, the power-law Eq. (4) is inspired e.g. by Eq. (4) in Hinkel et al. (2014) and by Eq. (7) in Fankhauser (1995). Regression fits were carried out using non-linear least-squares optimisation of the fit parameters applying the Levenberg-Marquardt algorithm (Marquardt, 1963). Using constraints of the parameters, we force the regressions to $C(0) \geq 0$ and to be monotonically increasing.

In Fig. 1a it can be seen for the Canadian data that the four models all have similar shapes and their deviations are small compared to the spread of the data. It is worth noting that the linear and the quadratic fits collapse; i.e. the best fit of Eq. (3) has a vanishing quadratic term $(c \approx 0)$ so that it becomes a linear regression identical to Eq. (2). Since our regression models vary strongly in the number of parameters $(1 \ldots 3)$, those with more parameters are expected to perform better in terms of root-mean-squared error (RMSE). Thus, in order to compensate for this advantage, we explore the Akaike information criterion (AIC) (Akaike, 1974), which evaluates the trade-off between goodness of fit and complexity of the models considered.

In Table 1 the fit parameters obtained and the resulting AIC and RMSE values are listed. For the Canadian data, the linear model without fixed costs, Eq. (2), performs best in terms of AIC, followed by the power-law model, Eq. (4), which generated the second lowest AIC value. The exponent obtained, however, indicates a curvature in the opposite direction to that expected from a quadratic polynomial due to the volume $(\beta \approx 0.7<1)$. The linear model, Eq. ( 2$)$, has an offset, $a$, with a standard error greater than the parameter itself, so it might be insignificant. As discussed above, the quadratic model, Eq. (3), is identical to the linear model (the quadratic contribution vanishes). It can be concluded that the fixed costs and contributions due to the volume are weaker than the spread. Linear regression also seems reasonable because all quantities contribute approximately linearly to the 
Table 1. Fit parameters according to Eq. (1)-(4), standard errors ( \pm ), and AIC and RMSE values for the regression types and parameter $\sigma$ of the log-normal distributions $(\mathcal{L N}$, Eq. 5) fitted to the residuals, for the data from Canada (Delcan Corporation, 2012) and the Netherlands (de Grave and Baase, 2011). The root-mean-squared error is calculated according to RMSE $=\sqrt{\frac{1}{n} \sum_{i=1}^{n}\left(Y_{i}-\hat{Y}_{i}\right)^{2}}$, where $\hat{Y}_{i}$ are the fitted values and $Y_{i}$ are the measured ones. For both AIC and RMSE, smaller values are better.

\begin{tabular}{|c|c|c|c|c|c|c|c|}
\hline \multirow[t]{2}{*}{ Fit } & \multicolumn{4}{|c|}{ Fit parameters } & \multirow[t]{2}{*}{ AIC } & \multirow[t]{2}{*}{ RMSE } & \multirow{2}{*}{$\begin{array}{c}\mathcal{L N} \\
\sigma\end{array}$} \\
\hline & $a$ & $b$ & $c$ & $\beta$ & & & \\
\hline \multicolumn{8}{|c|}{ Vancouver - all dikes (no. 28) } \\
\hline Linear, no intercept (LWI) & - & $5.7 \pm 0.6$ & - & - & 211.5 & 9.84 & $0.62 \pm 0.08$ \\
\hline Linear (LP) & $5.0 \pm 6.1$ & $4.3 \pm 1.8$ & - & - & 212.8 & 9.72 & - \\
\hline Quadratic (QP) & $5.2 \pm 19.1$ & $4.3 \pm 12.3$ & $0.0 \pm 1.8$ & - & 214.8 & 9.72 & - \\
\hline Power law (PL) & - & $8.4 \pm 3.4$ & - & $0.7 \pm 0.32$ & 212.6 & 9.69 & - \\
\hline \multicolumn{8}{|c|}{ Vancouver - new dikes (no. 14) } \\
\hline Linear, no intercept & - & $1.3 \pm 0.5$ & - & - & 95.3 & 2.40 & $0.90 \pm 0.19$ \\
\hline \multicolumn{8}{|c|}{ Vancouver - raise dikes (no. 14) } \\
\hline Linear, no intercept & - & $2.0 \pm 0.7$ & - & - & 122.9 & 4.01 & $1.03 \pm 0.19$ \\
\hline \multicolumn{8}{|c|}{ Vancouver - urban dikes (no. 21) } \\
\hline Linear, no intercept & - & $1.8 \pm 0.5$ & - & - & 166.8 & 4.53 & $0.97 \pm 0.15$ \\
\hline \multicolumn{8}{|c|}{ Vancouver - rural dikes (no. 7) } \\
\hline Linear, no intercept & - & $0.6 \pm 0.1$ & - & - & 21.0 & 2.11 & $0.50 \pm 0.13$ \\
\hline \multicolumn{8}{|c|}{ Netherlands (no. 205) } \\
\hline Linear, no intercept & - & $8.7 \pm 0.3$ & - & - & 1034.6 & 3.03 & $0.54 \pm 0.03$ \\
\hline Linear & $0.1 \pm 0.4$ & $8.6 \pm 0.5$ & - & - & 1043.5 & 3.02 & - \\
\hline Quadratic & $1.6 \pm 0.7$ & $5.2 \pm 1.4$ & $1.2 \pm 0.4$ & - & 1038.7 & 2.98 & - \\
\hline Power law & - & $8.7 \pm 0.3$ & - & $1.0 \pm 0.04$ & 1043.0 & 3.02 & - \\
\hline
\end{tabular}

costs, except earth fill, which contributes quadratically. The core material, however, represents a comparably small fraction of the total costs. Structural flood protection costs represent approximately $10 \%$ of the total costs and the earth fill costs represent approximately $85 \%$ of the former (see Sect. A1).

The regressions for the Netherlands data are shown in Fig. 1b. Again, the fits are very similar and only the quadratic model, Eq. (3), deviates in the upper range $h>3 \mathrm{~m}$. In Table 1 it can be seen that according to AIC, the linear model without offset, Eq. (1), performs best and the quadratic model, Eq. (3), does second best. Here, the power law, Eq. (4), and the linear model without intercept, Eq. (1), collapse. The power law fits best for $\beta \approx 1$ so that the two models are identical, which is also reflected in similar resulting parameters $b$. A quadratic contribution might only take effect for heights beyond the available $h$ range, which is in agreement with (Jonkman et al., 2013). Moreover, the linear model, Eq. (2), leads to a rather small offset $a \approx 0.1$ (in particular compared to the standard error of 0.4 ), so that it is almost identical to the regression without offset. Again, we can conclude that the linear contribution dominates and fixed costs as well as non-linear contributions from the dike volume can be disregarded; i.e. non-linearities are not necessary.

\subsection{Uncertainty}

While the regressions characterise the typical relation between dike height and costs, next we want to study the spread around the fits. These deviations of individual dikes are due to site-specific properties and design features that go beyond the height and length and are usually unavailable. Therefore, drawing the analogy with cost overruns, we employ lognormal distributions $\mathcal{L} \mathcal{N}(\mu, \sigma)$ (Chou et al., 2009) to characterise the spread.

Accordingly, we analyse the residuals of the fits as an estimate of the uncertainty. The residuals were calculated as the ratio of fitted to observed values. Then we fit log-normal probability distributions:

$$
\mathcal{L} \mathcal{N}(r ; \mu, \sigma)=\frac{1}{\sqrt{2 \pi} \sigma r} \exp \left(\frac{(\ln (r)-\mu)^{2}}{2 \sigma^{2}}\right)
$$


where $r=\frac{\hat{C}(h)}{C(h)}$ denotes the residuals, $\mu$ the location parameter, and $\sigma$ the scale parameter, using maximum likelihood estimation, and employ the Kolmogorov-Smirnov test to evaluate the goodness of fit.

Two features support the choice of the log-normal distribution in this context. First, the log-normal distribution by definition excludes negative values. Second, the statistical spread is relative (for the same reason). Instead of a fixed uncertainty e.g. in EUR, it is defined as a fraction, or percentage, which is plausible since bigger projects typically have larger absolute uncertainty.

For the Canadian and the Netherlands data, the estimated uncertainties are displayed together with the LWI regressions in Fig. 2. It can be seen that the uncertainty covers a rather large range that increases (due to the lognormal definition) from low to high dikes, achieving approximately EUR 10000-100 000 for dikes of approximately 4-6 $\mathrm{m}$ height (see Table 1 for the obtained parameters and Sect. 3.3).

In the log-log scale (insets of Fig. 2) one can see qualitatively that the regressions and uncertainties represent the data reasonably well. The cost for raising a dike in Canada by $1 \mathrm{~m}$ is estimated to be EUR 6000 , where the range between $3.4 x$ and $x / 3.4$ contains $95 \%$ of the uncertainty $(x \approx$ EUR 6000). Analogously, for the Netherlands, the estimate is about EUR 9000 with an uncertainty factor 2.9. Nevertheless, few values are located outside the $95 \%$ ranges, suggesting that the log-normal distribution might only be a first approximation.

The Canadian data also include information about whether the dikes are completely new or existing dikes are to be raised. In addition, the land use in terms of urban/rural is specified, which strongly affects the land price (see Sect. A1) and eventually the design of construction. Thus, we analyse the data separately according to these four categories (new/raise, urban/rural). Due to the small sample size, we cannot fully disentangle all combinations; e.g. "new" includes both urban and rural. We find that the fits for new and raised dikes are very similar but larger samples would be required to support this finding. In contrast, urban and rural dikes differ clearly in their costs and accordingly lead to different slopes. The resulting fit parameters, i.e. unit costs and $\log$ standard deviations, are also included in Table 1. For the Netherlands a similar difference between urban and rural has been reported by de Grave and Baase (2011). Mostly the land value causes a discrepancy between urban and rural dikes. The actual land value, however, is very site specific and is highly sensitive to land-use and socio-economic changes as discussed earlier.

\subsection{Comparison with results from other studies}

To compare our results with results from Hoozemans et al. (1993) and Jonkman et al. (2013) we converted all data to EUR for the Netherlands in 2012, involving three adjust-
Table 2. GDP per capita, purchasing power parity (PPP) GDP per capita, and mean exchange rates $\left(e_{i, \mathrm{USD}}\right)$ of 2012 (World Bank, 2016) for Canada, the Netherlands, and the USA, as well as the PPPadjusted exchange rates $e_{i, \mathrm{USD}}^{*}$ and $e_{i \text {,EUR }}^{*}$ The PPP-adjusted exchange rates give the amount of money in the currency of the country having the same purchasing power as USD 1.00 and EUR 1.00, respectively.

\begin{tabular}{lcrrrr}
\hline & $\begin{array}{c}\text { GDP } \\
(\mathrm{USD})\end{array}$ & $\begin{array}{c}\text { GDPPPP } \\
(\text { PPP-USD })\end{array}$ & $\begin{array}{c}e_{i, \mathrm{USD}} \\
\left(\mathrm{USD}^{-1}\right)\end{array}$ & $\begin{array}{c}e_{i, \mathrm{USD}}^{*} \\
\left(\mathrm{PPP}^{2} \mathrm{USD}\right)^{-1}\end{array}$ & $\begin{array}{c}e_{i, \mathrm{EUR}}^{*} \\
\left(\mathrm{EUR}^{-1}\right)\end{array}$ \\
\hline CA & 52733.5 & 42280.8 & CAD 1.00 & CAD 1.25 & CAD 1.51 \\
NL & 49128.1 & 46053.9 & EUR 0.78 & EUR 0.83 & EUR 1.00 \\
US & 51456.7 & 51456.7 & USD 1.00 & USD 1.00 & USD 1.20 \\
GB & 41294.5 & 37607.9 & GBP 0.63 & GPD 0.69 & GBP 0.83 \\
\hline
\end{tabular}

ments, namely currency, purchasing power, and reference year.

The easiest way of adjusting for different currencies would be to use the exchange rates. However, this does not take into account differences in purchasing power. Considering these, the exchange rates have to be adjusted. To do so, one method, used for example by the World Bank, is to adjust the exchange rate of a currency $i$ to US dollars (USD), $e_{i, \mathrm{USD}}$, by correcting it using purchasing power parities (PPP). The World Bank provides both the GDP and the PPP-adjusted

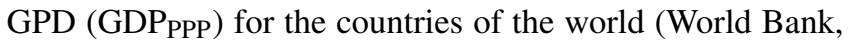
2016). Using these, a correction factor $c_{e}$ for the exchange rate can be derived by calculating the ratio of the GDP and the GDPPPP of a country according to $c_{e}=$ GDPPPP/GDP, leading to an evaluation of how much currency $i$ is over- or under-rated in comparison to USD. Then the given exchange rate $e_{i, \mathrm{USD}}$ can be corrected according to $e_{i, \mathrm{USD}}^{*}=e_{i, \mathrm{USD}} / c_{e}$, i.e. by dividing it by the correcting factor $c_{e}$. This gives the amount of currency $i$ one has to spend to have the same purchasing power as USD 1.00. To convert the PPP-adjusted exchange rate $e_{i, \mathrm{USD}}^{*}$ into EUR, it is divided by the PPPadjusted exchange rate $e_{\mathrm{EUR}, \mathrm{USD}}^{*}$ from EUR into USD, which can be derived as described above. This leads to the result of $e_{\mathrm{CAD}, \mathrm{EUR}}^{*}=1.51$ and $e_{\mathrm{USD}, \mathrm{EUR}}^{*}=1.20$ for 2012 , meaning that CAD 1.51 and USD 1.20 have the same purchasing power as EUR 1.00 in the Netherlands in 2012. Using these factors, the cost estimates given in CAD and USD can be converted into EUR.

For the data from Hoozemans et al. (1993) the USD prices of 1993 were adjusted to prices of 2012 first by using implicit price deflator values for the GDP of the USA from the US Federal Reserve Bank (Federal Reserve Bank of St. Louis, 2016). The price deflator index is set to $D_{2009}=100$ for 2009. For 1993 it is $D_{1993}=72.244$ and for 2012 it is $D_{2012}=105.231$. The cost for 2012 is calculated according to $C_{2012}=\left(C_{1993} \cdot D_{2012}\right) / D_{1993}$. Then these values were converted into EUR by dividing them by the PPP-adjusted exchange rate $e_{\mathrm{USD} \text {.EUR }}^{*}$ of Table 2 .

Jonkman et al. (2013) give the costs in EUR for 2009. To ensure comparability, these cost estimates were adjusted to 


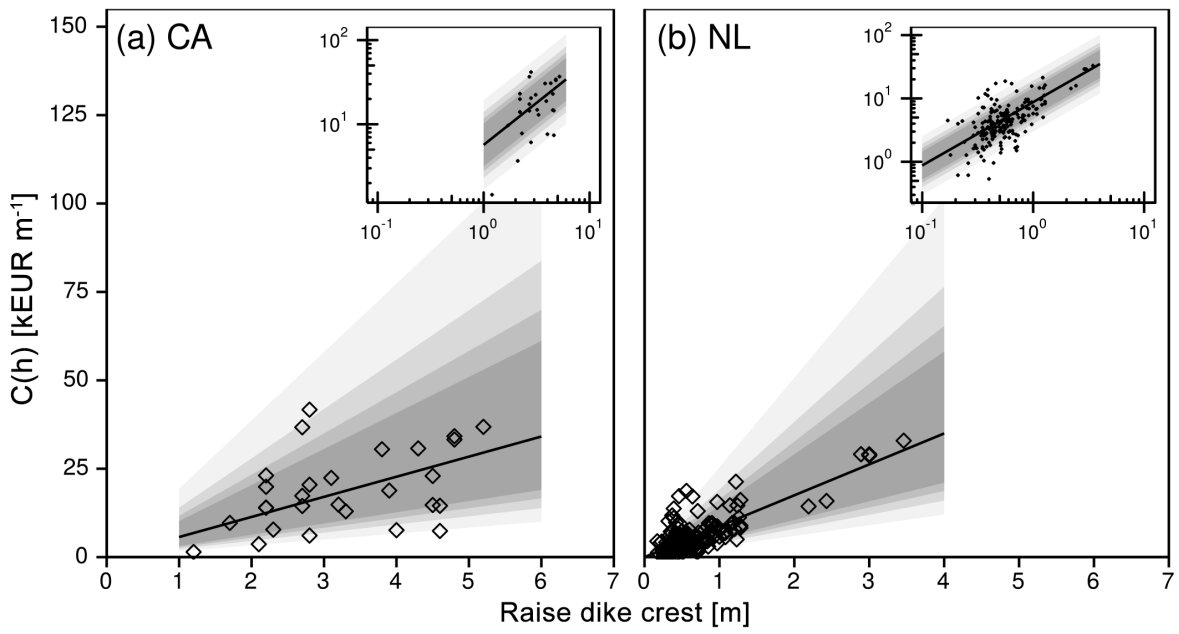

Figure 2. Spread of dike costs and estimated uncertainty. The dike costs are shown together with the linear regressions without intercept, Eq. (1), and with quantiles of estimated log-normal distributions. (a) Canadian dikes and (b) dikes in the Netherlands. The insets show the same items but in double logarithmic scale. The shades give the uncertainty inclosing estimated $95,85,75$, and $65 \%$ of the values (from light to dark).

values of 2012 by applying the same procedure using price deflators given by the US Federal Reserve Bank of St. Louis (Federal Reserve Bank of St. Louis, 2016). So the costs for 2012 is given by $C_{2012}=\left(C_{2009} \cdot D_{2012}\right) / D_{2009}$, where $C_{2009}$ is the cost given by Jonkman et al. (2013) and $D_{2009}=99.2$ and $D_{2012}=101.6$.

We also include results for Great Britain by using the dimensions of the dikes designed in the Canadian study to parameterise the calculation tool developed for the Environment Agency (Pettit and Robinson, 2012). We entered the dike dimensions and, utilising the 80th percentile of the costs, obtained estimations of the costs when the dikes specified in Delcan Corporation (2012) (Sect. 2.1) were built in Great Britain.

In Fig. 3 we compare the various values reported in the literature with our estimates in terms of $b$ (the slope) known as unit costs as described above. According to the available information, we separate dikes constructed on urban and rural land and those where land use is not specified. Moreover, we colour-code the five countries for which we have information, i.e. the Netherlands, Canada, the USA, Vietnam, and Great Britain. Where available, ranges and error bars (for $95 \%$ uncertainty) are plotted. It can be seen that the cost estimates by Hoozemans et al. (1993) are not in all cases underestimates as suggested by Jonkman et al. (2013). They line up quite well within the range of the other cost estimates for the Netherlands of de Grave and Baase (2011) and Jonkman et al. (2013). Further, it can be seen that the influence of land use, i.e. urban/rural, is smaller than the influence of the country where the dike is constructed. Nevertheless, when considering only individual countries there are still differences between land uses (as expected, urban dikes tend to be more expensive). Overall costs of dikes constructed in the Nether-

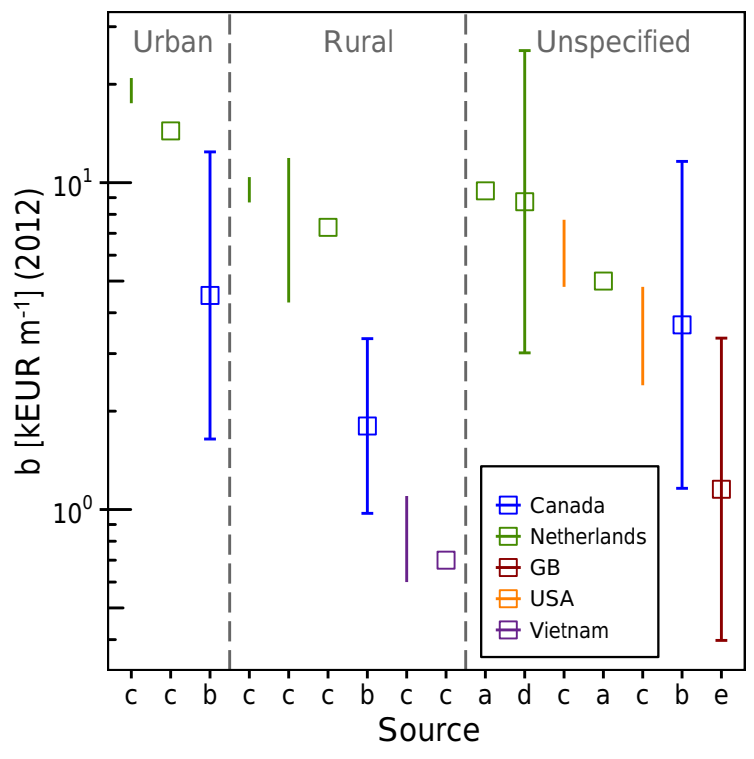

Figure 3. Comparison of our results with data from different studies and countries in terms of unit cost estimates for raising dikes, namely (a) Hoozemans et al. (1993), (b) our estimate based on Delcan Corporation (2012), (c) Jonkman et al. (2013), (d) our estimate based on de Grave and Baase (2011), and (e) our estimate based on Pettit and Robinson (2012) using data from Delcan Corporation (2012). Boxes represent single-unit cost estimates, plain bars give ranges, and the boxes with error bars indicate our calculations with mean and $95 \%$ quantiles of the log-normal distributions. To make the data comparable, the values have been adjusted to EUR of 2012. The studies differ partly in the components taken into account (see main text). Please note that the cost axis is logarithmic. The values are listed in Table B1. 
lands are the highest, followed by costs for dikes built in the USA, Canada, and Vietnam.

\section{Summary and discussion}

For both coastal protection projects, i.e. in Canada and the Netherlands, it is sufficient to express the typical costs of dikes per height and length, which is compatible with assumptions made in previous publications, e.g. in Jonkman et al. (2013). We offer a rigorous empirical basis for the assumption of constant unit costs (i.e. linear with height, no fixed costs). Moreover, we characterise the deviations of these typical costs with a log-normal distribution assuming the relative deviations are independent of height. This variability captures influences which go beyond the two strongest factors, namely length and height. Although the data from the Netherlands cover mostly dikes, or dike raises, of less than $1 \mathrm{~m}$, while the data from Canada include dikes as high as $7 \mathrm{~m}$, the uncertainty is of similar order of magnitude; i.e. in both cases the multiplication with and division by a factor of 3 includes approximately $95 \%$. In addition, we did not find statistical signatures of fixed costs or non-linearities for the dikes that we have analysed.

The uncertainty considered here stems from a lack of knowledge, i.e. by studying the costs only as a function of length and height, as we did not have more detailed information on the local conditions and requirements of the dikes available (although we assume that the authors of the reports did have greater knowledge). Hence, we borrow the concept of cost overruns to characterise the uncertainty of dike constructions. It is worth noting that erected constructions may be affected by real cost overruns (the original Canadian study included $50 \%$ contingency), which increase both the overall costs and the spread. Thus, in particular with regard to uncertainty, our results are probably only lower estimates. Another aspect to be considered is that we assume all dikes to have equal probability, i.e. each dot in Fig. 1 is equally likely. However, which dike design and corresponding costs are required depends on the local topography and their likelihood is characteristic of the case study. Moreover, we do not account for any economic shock that would affect the costs, e.g. raw material and fuel costs, labour shocks, shocks affecting imports.

We also want to discuss another aspect that comes into play: when the total costs of an ensemble of dikes are aggregated, e.g. according to $C_{\text {tot }}=\sum_{i} l_{i} C\left(h_{i}\right)$, where $i$ are the indices of dikes considered. Due to the central limit theorem, the standard deviation decreases with the square root of the sample size. If the costs of the dikes are independent of each other, then one can expect that the relative uncertainty will decrease with the number of dikes. In reality, however, it can be expected that the costs of different dikes are correlated so that the relative uncertainty of the total costs is likely not to shrink (Prahl et al., 2012, treat spatial correlations in a different context).

The transfer of our findings and conclusions to other countries needs to be done with caution. Although plausible, we have no proof that the analogous parameters and consequent conclusions hold true in other countries. In particular, it cannot be excluded that fixed costs could represent a significant contribution in countries with weaker tradition in coastal protection or in countries that so far have not been threatened by sea-level rise. Similar arguments could also apply to the unit costs. Further research is necessary to better understand the unit costs so that they can be transferred to other countries and circumstances.

In the context of riverine floods, the lack of good-quality cost estimates has hampered progress in the advance of largescale flood risk modelling. There is an urgent need for data on the location of dikes as well as their costs and uncertainty (Ward et al., 2015). Given the information of flood management in place (i.e. existing protection levels), this could be done by automatised identification of the required protection courses (Boettle et al., 2017, 2014), and our method and results could help to estimate the dike costs. Certainly, coastal and riverine dikes have different requirements, in particular regarding wave run-up and duration of floods. However, it is plausible that our main conclusions regarding linear cost function and uncertainty also apply to riverine dikes.

Comparing our estimates with the figures provided in the literature, we find that the costs differ more between the countries than between land uses. Nevertheless, within countries the differences due to land uses are pronounced and, as expected, urban dikes tend to be more costly than rural ones. However, when comparing such cost estimates it is crucial to note which components are actually included in the figures. While in the Canadian report (Delcan Corporation, 2012) all components of the costs are disclosed, in other cases it might not be clear whether, for example, costs of property acquisition or project management are included or whether they refer to the pure costs of the physical construction.

Costs of operation and maintenance are another complication. Such costs depend on frequency of inspections, annual maintenance requirements, and long-term intermittent maintenance activities (Keating et al., 2015). Typical activities include repairs, vegetation cutting, weed and vermin control, and maintenance costs, which can vary by over an order of magnitude (Keating et al., 2015). While the Netherlands data do include maintenance, the Canadian data and the Great Britain estimates do not. The annual operation costs are usually given as a percentage of the construction costs over the lifetime of the dike. If we assume $1 \%$ of annual maintenance costs over a lifetime of 100 years, then maintenance adds up to $100 \%$ of the construction costs (disregarding any discounting) so that maintenance can represent a substantial contribution to the costs. In terms of accounting, construction costs usually represent one-time expenses and operation costs are spread out over many years. 
To conclude, this study gives decision makers an order of magnitude on the protection costs which can remove potential barriers to designing and implementing adaptation strategies in other countries. Future research may focus on the creation of a "best practice" approach to understand how potential impacts are accounted for and to deliver to decision makers ways in which climate adaptation options such as sea dikes can be understood and measured, in terms of both investment needed economically and in reducing risks of flooding and reduced damage costs.
Data availability. The underyling research data are referenced in the papers (de Grave and Baase, 2011; Delcan Corporation, 2012; Pettit and Robinson, 2012). The resulting data are given in Table 1. 


\section{Appendix A: Explicit cost estimates}

\section{A1 Canada}

The total costs (from Table 4.2 in Delcan Corporation, 2012) consist of the following:

1. Structural flood protection/embankment consists of $9 \%$ of total costs. For a dike of length $l$, footprint $f$, and height $h$, the following components are included, while " $\sim$ " represents proportionality.

a. Site preparation: clearing and removal of topsoil (costs $/ l \sim h t$, where $t$ is the thickness of the layer) with an estimated unit cost of CAD $15 \mathrm{~m}^{-3}$.

b. Core material: supplying and installing the dike material (costs $/ l \sim f h$, approximately costs $/ l \sim h^{2}$ ) with an estimated unit cost of CAD $40 \mathrm{~m}^{-3}$.

c. Rip-rap: stone protection for the water side of the dike (costs $/ l \sim h t$, where $t$ is the thickness of the layer) with an estimated unit cost of CAD $50 \mathrm{~m}^{-3}$.

d. Surface restoration: construction of a typical asphalt road in case there is already a road at the site; this applies to $5 / 36$ reaches (costs $/ l \sim f \sim h$, assuming surface $\sim l f$ ) with an estimated unit cost of CAD $100 \mathrm{~m}^{-2}$.

2. Utility relocation, pump stations, and flood boxes consist of $4 \%$ of total costs.

a. It was assumed that dike construction will include $25 \%$ extra in urban areas and $5 \%$ for rural areas for utility relocation.

b. Upgrades of existing pump stations apply to $16 / 36$ reaches, with an estimated unit cost of CAD 2.5 million.

c. Adjustment of drainage behind the dike and small pump station installation applies to $18 / 36$ reaches, with an estimated unit cost of CAD 0.5 million.

3. Property acquisition consists of $17 \%$ of total costs. The area of property to be acquired is determined by the footprint, i.e. costs $/ l \sim f$, approximately costs $/ l \sim h$. Full purchase costs have been included, i.e. as derived from previous constructions. Residential property has double the value of commercial/industrial property and commercial/industrial property has 5 times the value of agricultural property.

a. Agricultural: $3 \%$ of total costs, $9 / 36$ reaches, $86 \%$ of total area, estimated unit cost of CAD $22 \mathrm{~m}^{-2}$;

b. Residential: $6 \%$ of total costs, $7 / 36$ reaches, $4 \%$ of total area, estimated unit cost of CAD $850 \mathrm{~m}^{-2}$;

c. Commercial/industrial: $8 \%$ of total costs, $11 / 36$ reaches, $11 \%$ of total area, estimated unit cost of CAD $400 \mathrm{~m}^{-2}$.
4. Seismic resilience (vibro-replacement, deep soil mixing, toe berm) consists of $34 \%$ of total costs.

Because the Vancouver area is seismically active, it is necessary to make dikes seismically resilient. Depending on the soil profile at the dike location vibroreplacement, deep soil mixing or installing a toe berm is necessary.

a. Vibro-replacement: 10/36 reaches, with an estimated unit cost of CAD $22 \mathrm{~m}^{-2}$;

b. Deep soil mixing: 3/36 reaches, with an estimated unit cost of CAD $250 \mathrm{~m}^{-2}$;

c. Toe berm: 10/36 reaches.

5. Environmental compensation consists of $1 \%$ of total costs and 4/36 reaches, with an estimated unit cost of CAD $250 \mathrm{~m}^{-2}$.

6. Site investigation, project management, and engineering ( $15 \%$ on top of previous items) consist of $2 \%$ of total costs.

7. Contingency (50\% on top of all previous items) consists of $33 \%$ of total costs.

Prior to beginning the analysis, we perform a few steps:

- exclude the following reaches: nos. 4 (floodwall), 5 (flood proofing, no information), 10 (barrier), 16 (double dike), 17 (flood proofing, no information), 23 (retreat), 27 (barrier), 28 (flood proofing, no information);

- disregard deep soil mixing of reaches 7, 8, and 22; and

- disregard 50\% contingency on top of the total costs.

This leads to a total of 28 reaches being analysed.

\section{A2 Netherlands}

The dike raising costs of the Dutch study are based on a system of cost functions. To obtain the cost function for one dike reach there are eight calculation steps taken into account:

1. Identify the needed dike height raising by modelling the hydraulic strain for a given dike height and return level interval.

2. Process the information about the current and the required dike profile to determine the needed ground and construction measures. This step takes into account:

a. the dike height of the initial situation,

b. the benching height of the initial situation if there is benching on the land side,

c. the distance between the outer dike crest and the dike foot on the land side, 
d. the required raising of the base body of the dike (corresponding to the required raising of the dike crest including an additional raising for settling and compaction),

e. broadening of the dike base for increasing macrostability, and

f. broadening of the dike base for piping.

3. Determine the range of ground and construction measures according to a four step expulsion list with the following combinations of measures:

M1 complete solution with exclusively ground measures,

M2 raising and fortification of the dike body with a combination of ground measures and one construction measure on the dike toes on the land side,

M3 dike raising in the ground and steepening of the (inside) embankment on one side in combination with one construction measure within the dike body, and

M4 dike raising in the ground and steepening of both dike embankments in combination with a cofferdam construction within the dike body.

According to the selected combination of measures, the new dike profile, the type and extent of the required construction measures, the additional footprint of the dike, the direct ground work and construction costs per unit of length, the length of the dike section to which the measures are applied, the total construction costs, and the additional costs for administration and maintenance are calculated.

4. Calculate the costs needed for dike reaches with special conditions. These special conditions consist of the construction of a cofferdam. The costs for this is estimated using both the horizontal and vertical length, the height and a standard cost function.
5. Estimate the costs needed for the adjustment of infrastructure. This applies if there is an existing road or other type of traffic infrastructure which has to be reallocated. This also applies if there are crossroads or railways located above the dike which interfere with the raising of the dike. This may require the construction of a new dike section.

6. Identify costs for purchase of land. To estimate this kind of costs there are four cases which are being differentiated, namely built-up area, non built-up area, urban, and rural. For the two categories built-up and urban the land acquisition costs are considered to be high and for non built-up and rural comparatively low.

7. Determine costs for countryside and environment compensation measures. If a dike reach crosses a nature reserve or an area of special scenic importance, it is necessary to acquire land create appropriate compensation measures.

8. Estimate the volume of the total investment costs and additional annual costs for administration and maintenance. The total investment costs are formed by summing up the costs (including their administration and maintenance costs) of the previous seven steps. Based on this, the total administration and maintenance costs are defined as percentage of the total investment costs.

\section{Appendix B: Overview of cost estimates}

In Table B1 we provide our estimated unit costs in comparison with values found in the literature. See also Fig. 3. 
Table B1. Comparison of different cost estimations for raising a dike of length $1 \mathrm{~km}$ for a height of $1 \mathrm{~m}$ for different land uses and different dike types. Land use and dike types are labelled here when available. All values have been converted into 2012 Euros to make them comparable. See also Figure 3 in the main text.

\begin{tabular}{|c|c|c|c|c|}
\hline Country & Land use & Dike type & $\begin{array}{l}\text { Cost estimate } \\
\left(\mathrm{kEUR} \mathrm{m}^{-1}\right)(2012)\end{array}$ & Source \\
\hline Canada & urban & - & $4.5(1.6-12.4)^{*}$ & our estimate based on Delcan Corporation (2012) \\
\hline Canada & rural & - & $1.8(1.0-3.3)^{*}$ & our estimate based on Delcan Corporation (2012) \\
\hline Canada & - & - & $3.7(1.2-11.6)^{*}$ & our estimate based on Delcan Corporation (2012) \\
\hline GB & - & - & $1.2(0.4-3.3)^{*}$ & our estimate based on Pettit and Robinson (2012) \\
\hline GB & - & small dike $<500 \mathrm{~m}^{3}$ & $\leq 0.14$ & Keating et al. (2015) \\
\hline GB & - & medium dike $500-5000 \mathrm{~m}^{3}$ & $\overline{0} .01-0.96$ & Keating et al. (2015) \\
\hline GB & - & large dike $5000-15000 \mathrm{~m}^{3}$ & $0.55-16.67$ & Keating et al. (2015) \\
\hline GB & - & very large dike $>15000 \mathrm{~m}^{3}$ & $\geq 1.16$ & Keating et al. (2015) \\
\hline Netherlands & - & - & $\overline{5} .6(3.0-25.4)^{*}$ & our estimate based on de Grave and Baase (2011) \\
\hline Netherlands & - & dune & 1.3 & Hoozemans et al. (1993) \\
\hline Netherlands & - & bund & 0.3 & Hoozemans et al. (1993) \\
\hline Netherlands & - & sea dike (toe at $0 \mathrm{~m}$ ) & 5.0 & Hoozemans et al. (1993) \\
\hline Netherlands & - & sea dike (toe at $5 \mathrm{~m}$ ) & 9.4 & Hoozemans et al. (1993) \\
\hline Netherlands & rural & - & $9.6-11.5$ & Kok et al. (2008) in Jonkman et al. (2013) \\
\hline Netherlands & rural & - & $4.7-13.8$ & Eijgenraam (2006) in Jonkman et al. (2013) \\
\hline Netherlands & rural & - & 8.0 & Arcadis and Fugro (2006) in Jonkman et al. (2013) \\
\hline Netherlands & urban & - & $19.2-23.0$ & Kok et al. (2008) in Jonkman et al. (2013) \\
\hline Netherlands & urban & - & 15.9 & Arcadis and Fugro (2006) in Jonkman et al. (2013) \\
\hline USA & - & earthen dike & $5.3-8.4$ & Dijkman (2007), Jonkman et al. (2009) \\
\hline USA & - & earthen dike & $4.6-5.3$ & USACE (2011) in Jonkman et al. (2013) \\
\hline USA & - & earthen dike & $4.6-9.6$ & USACE (2011) in Jonkman et al. (2013) \\
\hline Vietnam & rural & - & $0.7-1.2$ & Hillen (2008) in Jonkman et al. (2013) \\
\hline Vietnam & rural & - & 0.8 & Mai et al. (2008) in Jonkman et al. (2013) \\
\hline
\end{tabular}

* This range includes $95 \%$ of the estimated uncertainty. 
Competing interests. The authors declare that they have no conflict of interest.

Acknowledgements. We thank H. Costa, G. Floater, R. J. Meijer, and Boris F. Prahl for useful discussions, M. Olonscheck for her translation skills, and C. J. Hewett for help with the manuscript. The research leading to these results has received funding from the European Community's Seventh Framework Programme under grant agreement no. 308497 (Project RAMSES). The publication of this article was funded by the Open Access Fund of the Leibniz Association.

Edited by: B. Merz

Reviewed by: two anonymous referees

\section{References}

Aerts, J. C. J. H., Botzen, W. J. W., Moel, H. d., and Bowman, M.: Cost estimates for flood resilience and protection strategies in New York City, Ann. NY Acad. Sci., 1294, 1-104, doi:10.1111/nyas.12200, 2013.

Akaike, H.: A new look at the statistical model identification, IEEE T. Automat. Contr., AC-19, 716-723, doi:10.1109/TAC.1974.1100705, 1974.

Arcadis and Fugro: Kostenfuncties Dijkringgebieden 7, 14, en 29, Report, Ministry of Transport, Public Works and Water Management, Amersfoort, Netherlands, in Dutch, 2006.

BCIS: Elemental Standard Form of Cost Analysis, Royal Instituttion of Chartered Surveyors, London, 4th Edn., available at: http://www.rics.org/Global/BCIS_Elemental_Standard_Form_ of_Cost_Analysis_4th_NRM_Edition_2012.pdf (last access: 7 May 2017), 2012.

Boettle, M., Rybski, D., and Kropp, J. P.: How changing sea level extremes and protection measures alter coastal flood damages, Water Resour. Res., 49, 1199-1210, doi:10.1002/wrcr.20108, 2013a.

Boettle, M., Rybski, D., and Kropp, J. P.: Adaptation to Sea Level Rise: Calculating Costs and Benefits for the Case Study Kalundborg, Denmark, in: Climate Change Adaptation in Practice, edited by: Schmidt-Thomé, P. and Klein, J., Wiley-Blackwell, Chichester, UK, chap. 3, 25-34, 2013b.

Boettle, M., Costa, L., Kriewald, S., Kropp, J. P., Prahl, B. F., and Rybski, D.: Development of a library of impact functions and general uncertainty measures (Deliverable 1.2), Tech. rep., RAMSES project: Reconciling Adaptation, Mitigation and Sustainable Development for Cities, available at: http://www.ramses-cities.eu/fileadmin/uploads/Deliverables_ Uploaded/Development_of_a_library_of_impact_functions_ and_general_uncertainty_measures_D1.2.pdf (last access: 7 May 2017), 2014.

Boettle, M., Rybski, D., and Kropp, J. P.: Quantifying the effect of sea level rise and flood defence - a point process perspective on coastal flood damage, Nat. Hazards Earth Syst. Sci., 16, 559576, doi:10.5194/nhess-16-559-2016, 2016.

Prahl, B. F., Boettle, M., Costa, L., Kropp, J. P., and Rybski, D.: Damage and protection cost curves for coastal floods in the largest European cities, in preparation, 2017.
Bouwer, L. M.: Projections of Future Extreme Weather Losses Under Changes in Climate and Exposure, Risk. Anal., 33, 915-930, doi:10.1111/j.1539-6924.2012.01880.x, 2013.

Chou, J.-S., Yang, I.-T., and Chong, W. K.: Probabilistic simulation for developing likelihood distribution of engineering project cost, Automat. Constr., 18, 570-577, doi:10.1016/j.autcon.2008.12.001, 2009.

Dawson, R. and Hall, J.: Adaptive importance sampling for risk analysis of complex infrastructure systems, P. Roy. Soc. A Math. Phy., 462, 3343-3362, doi:10.1098/rspa.2006.1720, 2006.

Dawson, R. J., Dickson, M. E., Nicholls, R. J., Hall, J. W., Walkden, M. J. A., Stansby, P. K., Mokrech, M., Richards, J., Zhou, J., Milligan, J., Jordan, A., Pearson, S., Rees, J., Bates, P. D., Koukoulas, S., and Watkinson, A. R.: Integrated analysis of risks of coastal flooding and cliff erosion under scenarios of long term change, Climatic Change, 95, 249-288, doi:10.1007/s10584008-9532-8, 2009.

Dawson, R. J., Ball, T., Werritty, J., Werritty, A., Hall, J. W., and Roche, N.: Assessing the effectiveness of non-structural flood management measures in the Thames Estuary under conditions of socio-economic and environmental change, Global Environ. Chang., 21, 628-646, doi:10.1016/j.gloenvcha.2011.01.013, 2011.

de Grave, P. and Baase, G.: Kosten van maatregelen, technical report, Deltares, Delft, Netherlands, 2011.

Delcan Corporation: Cost of Adaptation - Sea Dikes \& Alternative Strategies, FINAL REPORT EB3762, British Columbia Ministry of Forests, Lands and Natural Resource Operations, Vancouver, available at: http://www.env.gov.bc.ca/wsd/public_safety/flood/ pdfs_word/cost_of_adaptation-final_report_oct2012.pdf (last access: 7 May 2017), 2012.

Diaz, D. B.: Estimating global damages from sea level rise with the Coastal Impact and Adaptation Model (CIAM), Climatic Change, 137, 143-156, doi:10.1007/s10584-016-1675-4, 2016.

Dijkman, J.: A Dutch Perspective on Coastal Louisiana Flood Risk Reduction and Landscape Stabilization, Report WL-Z4307 prepared for the United States Army European Research Office, Netherlands Water Partnership, Delft, Netherlands, 2007.

Dronkers, J., Gilbert, J. T. E., Butler, L., Carey, J. J., Campbell, J., James, E., McKenzie, C., Misdorp, R., Quin, N. Ries, K. L., Schroder, P. C., Spradley, J. R., Titus, J. G., Vallianos, L., and von Dadelszen, J.: Strategies for Adaption to Sea Level Rise, Report, IPCC Coastal Zone Management Subgroup: Intergovernmental Panel on Climate Change, Geneva, available at: http://papers.risingsea.net/ IPCC-1990-Strategies-for-Adaption-to-Sea-Level-Rise.html (last access: 7 May 2017), 1990.

Eijgenraam, C., Kind, J., Bak, C., Brekelmans, R., den Hertog, D., Duits, M., Roos, K., Vermeer, P., and Kuijken, W.: Economically Efficient Standards to Protect the Netherlands Against Flooding, Interfaces, 44, 7-21, doi:10.1287/inte.2013.0721, 2014.

Eijgenraam, C. J. J.: Optimal safety standards for dike-ring areas, Discussion paper, CPB Netherlands Bureau for Economic Policy Analysis, Den Haag, Netherlands, 2006.

Eijgenraam, C. J. J. and Zwaneveld, P. J.: Second Opinion Kostenbatenanalyse Waterveiligheid 21e eeuw, CPB notitie, Centraal Planbureau, Den Haag, Netherlands, 2011. 
Fankhauser, S.: Protection versus retreat: the economic costs of sealevel rise, Environ. Plann. A, 27, 299-319, doi:10.1068/a270299, 1995.

Federal Reserve Bank of St. Louis: Gross Domestic Product: Implicit Price Deflator, available at: https://research.stlouisfed.org/ fred2/series/GDPDEF, last access: 1 March 2016.

Flyvbjerg, B.: Policy and Planning for Large-Infrastructure Projects: Problems, Causes, Cures, Environ. Plann. B, 34, 578597, doi:10.1068/b32111, 2007a.

Flyvbjerg, B.: Cost Overruns and Demand Shortfalls in Urban Rail and Other Infrastructure, Transport. Plan. Techn., 30, 9-30, doi:10.1080/03081060701207938, 2007b.

Flyvbjerg, B. and Stewart, A.: Olympic Proportions: Cost and Cost Overrun at the Olympics 1960-2012, Working paper, Saïd Business School - University of Oxford, Oxford, doi:10.2139/ssrn.2238053, 2012.

Hallegatte, S., Green, C., Nicholls, R. J., and Corfee-Morlot, J.: Future flood losses in major coastal cities, Nature Climate Change, 3, 802-806, doi:10.1038/nclimate1979, 2013.

Heidrich, O., Dawson, R. J., Reckien, D., and Walsh, C. L.: Assessment of the climate preparedness of 30 urban areas in the UK, Climatic Change, 120, 771-784, doi:10.1007/s10584-013-08469, 2013.

Heidrich, O., Reckien, D., Olazabal, M., Foley, A., Salvia, M., Gregorio Hurtado, S. d., Orru, H., Flacke, J., Geneletti, D., Pietrapertosa, F., Hamann, J. J.-P., Tiwary, A., Feliu, E., and Dawson, R. J.: National climate policies across Europe and their impacts on cities strategies, J. Environ. Manage., 168, 36-45, doi:10.1016/j.jenvman.2015.11.043, 2016.

Hillen, M. M.: Safety Standards Project, Risk Analysis for New Sea Dike Design Guidelines in Vietnam, technical report, Delft University of Technology, Hanoi Water Ressources University, 2008.

Hinkel, J., Lincke, D., Vafeidis, A. T., Perrette, M., Nicholls, R. J., Tol, R. S. J., Marzeion, B., Fettweis, X., Ionescu, C., and Levermann, A.: Coastal flood damage and adaptation costs under 21st century sea-level rise, P. Natl. Acad. Sci. USA, 111, 3292-3297, doi:10.1073/pnas.1222469111, 2014.

Hoozemans, F. M. J., Marchand, M., and Pennekamp, H. A.: A Global Vulnerability Analysis: Vulnerability Assessment for Population, Coastal Wetlands and Rice Production on a Global Scale, Delft Hydraulics, Delft, the Netherlands, 1993.

Hudson, T., Keating, K., and Pettit, A.: Cost estimation for coastal protection - summary of evidence, Report SC080039/R7, Environment Agency, Bristol, available at: https: //www.gov.uk/government/uploads/system/uploads/attachment_ data/file/411178/Cost_estimation_for_coastal_protection.pdf (last access: 7 May 2017), 2015.

Jongmann, B., Hochrainer-Stigler, S., Feyen, L., Aerts, J. C. J. H., Mechler, R., Botzen, W. J. W., Bouwer, L. M., Pflug, G., Rojas, R., and Ward, P. J.: Increasing stress on disaster-risk finance due to large floods, Nature Climate Change, 4, 264-268, doi:10.1038/NCLIMATE2124, 2014.

Jonkman, S. N., Brinkhuis-Jak, M., and Kok, M.: Cost benefit analysis and flood damage mitigation in the Netherlands, Heron, 49, 95-111, 2004.

Jonkman, S. N., Maskaant, B., Boyd, E., and Levitan, M. L.: Loss of life caused by the flooding of New Orleans after hurricane Katrina: analysis of the relationship between flood characteris- tics and mortality, Risk. Anal., 5, 676-698, doi:10.1111/j.15396924.2008.01190.x, 2009.

Jonkman, S. N., Hillen, M. M., Nicholls, R. J., Kanning, W., and van Ledden, M.: Costs of Adapting Coastal Defences to Sea-Level Rise- New Estimates and Their Implications, J. Coastal Res., 29, 1212-1226, doi:10.2112/JCOASTRES-D-12-00230.1, 2013.

Keating, K., Pettit, A., and Wood, A.: Cost estimation for fluvial defences - summary of evidence, Research Contractor Report SC080039/R2, Environment Agency, Bristol, UK, available at: https://www.gov.uk/government/uploads/system/uploads/ attachment_data/file/411171/Cost_estimation_for_fluvial_ defences.pdf (last access: 7 May 2017), jBA Consulting, 2015.

Kind, J. M.: Economically efficient flood protection standards for the Netherlands, J. Flood Risk Management, 7, 103-117, doi:10.1111/jfr3.12026, 2014.

Klijn, F., Knoop, J. M., Ligtvoet, W., and Mens, M. J. P.: In search of robust flood risk management alternatives for the Netherlands, Nat. Hazards Earth Syst. Sci., 12, 1469-1479, doi:10.5194/nhess-12-1469-2012, 2012.

Kok, M., Jonkman, S., Kanning, W., Stijnen, J., and Rijcken, T.: Toekomst voor het Nederlandse polderconcept, Annex to "Working Together with Water", Delta Comittee, Den Haag, Netherlands, in Dutch, 2008.

Kreibich, H., van den Berg, J. C. J. M., Bouwer, L. M., Bubeck, P., Ciavola, P., Green, C., Hallegatte, S., Logar, I., Meyer, V., Schwarze, R., and Thieken, A. H.: Costing Natural Hazards, Nature Climate Change, 4, 303-306, doi:10.1038/nclimate2182, 2014.

Linham, M. M., Green, C. H., and Nicholls, R. J.: Costs of adaptation to the effects of climate change in the world's large port cities, Report AV/WS2/D1/R14, AVOID: Avoiding dangerous climate change, available at: http://www.avoid.uk.net/2010/07/avoid-1-costs-of-adaptationto-the-effects-of-climate-change-in-the-worlds-large-port-cities/ (last access: 7 May 2017), work stream 2, 2010.

Love, P. E. D., Wang, X., Sing, C.-P., and Tiong, R. L. K.: Determining the Probability of Project Cost Overruns, J. Constr. Eng. Manage., 139, 321-330, doi:10.1061/(ASCE)CO.19437862.0000575, 2013.

MacDonald, M.: CESMM4 Carbon \& Price Book 2013, ICE Publishing, London, doi:10.1680/ccpb2013.58125, 2013.

Mai, C. V., van Gelder, P. H. A. J. M., Vrijling, J. K., and Mai, T. C.: Risk analysis of coastal flood defences: a Vietnam case, in: Proceedings of the 4th International Symposium on Flood Defence (Toronto, Canada, Institute for Catastrophic Loss Reduction), 931-938, 2008.

Marquardt, D. W.: An Algorithm for Least-Squares Estimations of Nonlinear Parameters, J. Soc. Ind. Appl. Math., 11, 431-441, 1963.

Menéndez, M. and Woodworth, P. L.: Changes in extreme high water levels based on a quasi-global tide-gauge data set, J. Geophys. Res., 115, C10011, doi:10.1029/2009JC005997, 2010.

Pettit, A. and Robinson, P.: Supporting Spreadsheet for the Long Term Costing Project, in: Flood and Coastal Erosion Risk Management Research and Development Programme, JBA Consulting and Environment Agency (EA), Environment Agency (EA), Bristol, UK, 2012.

Prahl, B. F., Rybski, D., Kropp, J. P., Burghoff, O., and Held, H.: Applying stochastic small-scale damage functions 
to German winter storms, Geophys. Res. Lett., 39, L06806, doi:10.1029/2012GL050961, 2012.

Prahl, B. F., Rybski, D., Boettle, M., and Kropp, J. P.: Damage functions for climate-related hazards: unification and uncertainty analysis, Nat. Hazards Earth Syst. Sci., 16, 1189-1203, doi:10.5194/nhess-16-1189-2016, 2016.

Public Works and Government Services Canada: Cost estimation definitions, available at: http://www.tpsgc-pwgsc.gc. ca/biens-property/sngp-npms/bi-rp/conn-know/couts-cost/ definition-eng.html (last access: 18 January 2016), last modified 2 March 2015.

Reckien, D., Flacke, J., Olazabal, M., and Heidrich, O.: The Influence of Drivers and Barriers on Urban Adaptation and Mitigation Plans-An Empirical Analysis of European Cities, PLoS One, 10, 1-21, doi:10.1371/journal.pone.0135597, 2015.

USACE: Louisina Coastal Protection and Restoration (LAPCR), final technical report, US Army Corp of Engineers, available at: http://www.mvn.usace.army.mil/Portals/56/docs/environmental/ LaCPR/LACPRFinalTechnicalReportJune2009.pdf (last access: 21 May 2017), 2011.
Vousdoukas, M. I., Voukouvalas, E., Mentaschi, L., Dottori, F., Giardino, A., Bouziotas, D., Bianchi, A., Salamon, P., and Feyen, L.: Developments in large-scale coastal flood hazard mapping, Nat. Hazards Earth Syst. Sci., 16, 1841-1853, doi:10.5194/nhess-161841-2016, 2016.

Ward, P. J., Jongman, B., Salamon, P., Simpson, A., Bates, P., De Groeve, T., Muis, S., de Perez, E. C., Rudari, R., Trigg, M. A., and Winsemius, H. C.: Usefulness and limitations of global flood risk models, Nature Climate Change, 5, 712-715, doi:10.1038/nclimate2742, 2015.

World Bank: World Development Indicators, available at: http: //data.worldbank.org/indicator/NY.GDP.MKTP.PP.CD, last access: 1 March 2016. 